\title{
Ant Colony Algorithm Based Fault Pattern Optimization in Test Verification
}

\author{
Chenglin Yang ${ }^{1 *}$, Cheng Liu ${ }^{1}$ and Fang Chen ${ }^{2}$ \\ ${ }^{1}$ University of Electronic Science and Technology of China, Chengdu, Sichuan, P.R.China \\ ${ }^{2}$ Chengdu College of UESTC, Chengdu, Sichuan, P.R.China \\ ${ }^{*}$ Corresponding author
}

\begin{abstract}
With the ever-increasing design scales of electronic products and weapons, it is essential to make a design for testability (DFT) in the process of product research and development. To confirm the correctness of testability design and analysis, it is necessary to perform testability verification for the product. Testability verification refers to those work conducted for examining whether the designed products meet testability requirement or the test and analysis to ascertain whether the equipment is up to the testability demand. As a result, testability verification has become an important tool for identifying the defects of the design, checking whether the product is fully implemented. In testability verification, the mode of failure is a low failure rate, but if it happens, it will spread to other components, which will affect the scale of the impact. Once it happens, the fault will propagate and spread to other elements and cause huge impact. If the DFT about propagated fault is incomplete, once the propagated fault happens but not be detected and isolated correctly, the threats of the propagated fault to consumers are roughly the same with the total usual risks. So it should make an important sampling to the propagated fault during extracting failure mode to reduce the consumers' risk. Therefore, in order to reduce the risk of the use of the transmission mode, we should do the important sampling of the fault mode. In this paper, a fault propagation model is established, which is based on the fault propagation model set that is based on fault propagation. Then it describes the principle of fault propagation, and finally through the ant colony algorithm, this paper solves the fault propagation path and optimizes selection of fault sample mode.
\end{abstract}

Keywords-testability verification; testability integrated evaluation; failure sample optimization selection; failure propagation; ant colony algorithm

\section{INTRODUCTION}

Testability verification is based on fault detection, fault isolation and the corresponding results to implement [1,2]. It's far from meeting the sample number that designed by verification scheme in the case of only detecting natural fault. So it's essential to introduce fault artificial, which is called fault simulation.

Before performing the testability verification, we need to confirm the total workflow so that we can ascertain test samples, specified fault injection and recorded and evaluated data. Technically, the testability verification mainly includes the following three aspects: (1)The scheme design for testability verification experiment, that is, to confirm the fault sampling scheme;(2) The implement of the testability verification experiment, the key is to perform fault inject; (3)The evaluation of testability index.

\section{A. Confirm the Testability Demonstration Scheme}

At first, we must randomly select test sample amount. For example, $\mathrm{n}$ samples are selected to make test, $\mathrm{F}$ times fail. Specify a positive integer $\mathrm{C}$, if $\mathrm{F}<\mathrm{C}$, it's considered to be standard, then be judged to accept; otherwise it's below standard. Confirming sampling scheme is to ascertain ' $n$ ' and ' $c$ ' at the same time.

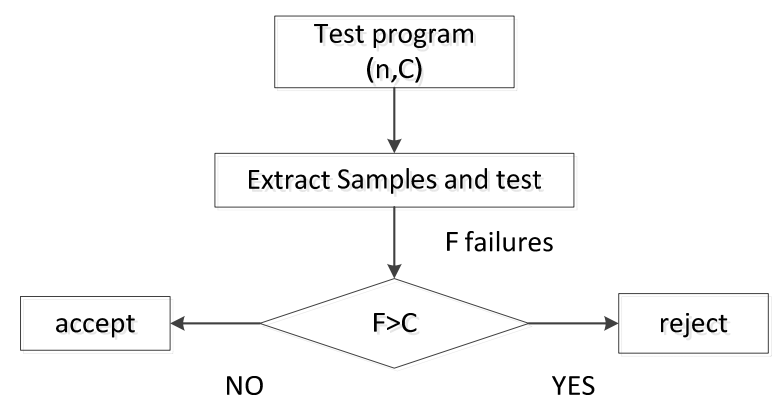

FIGURE I. DESIGN OF TEST PROGRAM

In the sampling trial, if the successful probability is q, then the probability of occurring $\mathrm{F}$ fails in $\mathrm{n}$ trials is:

$$
P(\mathrm{q} ; \mathrm{n}, \mathrm{F})=\mathrm{C}_{n}^{F}(1-\mathrm{q})^{F} q^{n-F}
$$
is:

The total probability of fails no more than $\mathrm{C}$ in $\mathrm{n}$ samples

$$
\mathrm{L}(\mathrm{q})=\sum_{F=0}^{C} p(\mathrm{q} ; \mathrm{n}, \mathrm{F})
$$

The probability of receiving different $\mathrm{q}$ call Operation Characteristic, denoted by $\mathrm{L}(\mathrm{q})$. The function relation of $\mathrm{L}(\mathrm{q})$ and $\mathrm{q}$ is called Operating Characteristic function.

B. RelationalModeling of Sampling Scheme (n, c)between Producer's Risk ( $\alpha)$ and Consumer's Risk $(\beta)$

The consumers select an extreme quality level q1 corresponding to a certain lower probability [4]. It is not 
accepted if the quality is less good than extreme quality level. Because of inevitable drawbacks in the sampling scheme, there is a little probability to be wrong judged as reception. The probability of acceptance in the case of extreme quality level is called consumer's risk, denoted by $\beta$.

The producers can't implement testability design with extreme quality; otherwise the probability of refusing is much bigger. To make the design of equipment to achieve satisfied design quality level q0, so that it's accepted by great probability with $\mathrm{q} 0$. But there is a little probability to be refused. When achieving satisfactory quality, refused probability is called producer's risk, denoted by $\alpha$.

On the base of confirming the design value q0, the lowest accepted value q1, producer's risk $\alpha$ and consumer's risk by negotiating between the producers and consumers, the sampling scheme can be ascertained using the following simultaneous equations. After that, the value of $n$ and $\mathrm{c}$ is got.

$$
\left\{\begin{array}{l}
\mathrm{L}\left(\mathrm{q}_{1}\right)=\sum_{F=0}^{C} \mathrm{C}_{n}^{F}\left(1-\mathrm{q}_{1}\right)^{F} q_{1}{ }^{n-F}=\beta \\
1-\mathrm{L}\left(\mathrm{q}_{0}\right)=\sum_{F=0}^{C} \mathrm{C}_{n}^{F}\left(1-\mathrm{q}_{0}\right)^{F} q_{0}{ }^{n-F}=\alpha
\end{array}\right.
$$

As in the practical application $\mathrm{n}$ and $\mathrm{c}$ must be positive integers, these positive integers which just satisfy the above equations may not necessarily exist. Generally we should calculate the minimum of $\mathrm{n}$ and $\mathrm{C}$ values meet the simultaneous equations, namely the relation model.

$$
\left\{\begin{array}{l}
\mathrm{L}\left(\mathrm{q}_{1}\right)=\sum_{F=0}^{C} \mathrm{C}_{n}^{F}\left(1-\mathrm{q}_{1}\right)^{F} q_{1}{ }^{n-F} \leq \beta \\
1-\mathrm{L}\left(\mathrm{q}_{0}\right)=\sum_{F=0}^{C} \mathrm{C}_{n}^{F}\left(1-\mathrm{q}_{0}\right)^{F} q_{0}{ }^{n-F} \leq \alpha
\end{array}\right.
$$

\section{Sampling Program (n,c) Distributes the Fault Samples by the Proportional Layering}

Stratified sampling can be called that the sampling is done in each layer and the total samples are consisted of each layer samples, the population parameters are estimated by the sample parameters of each layer. Samples obtained by stratified sampling is called stratified sample [5,6,7]. The method of allocating failure sample size in every layer in testability validation protocols first analyses the under-test device is composed by what layers, then gets the failure rate of each layer and in each layer the allocated failure sample will distribute the total sample size $n$ to each replaceable unit of the equipment specified level by the weights $\mathrm{Wi}$ of failure rate. Using the same methods we also distribute the failure samples of each replaceable unit to the lower replaceable unit. It shows in the blow formula:

$$
\left\{\begin{array}{l}
n_{i}=n * W_{i} \\
W_{i}=\frac{Q_{i} \lambda_{i} T_{i}}{\sum_{i} Q_{i} \lambda_{i} T}
\end{array}\right.
$$

$W_{i}$ — the assign weights of $\mathrm{i}$-th unit.

$Q_{i}$ - the number of i-th unit, describe the complex of equipment.

$\lambda_{i} \longrightarrow$ the failure rate of $\mathrm{i}$-th unit.

$T_{i}$ the working time coefficient of i-th unit, the working time than the working full time.

\section{PRINCIPLE OF FAUlt PATtern OPtimization IN TESTABILITY VERIFICATION}

\section{A. Definition of Signal Flow Diagram Model}

Signal flow diagram model based on system failure propagation is obtained from analyzing electronic circuit system structure, this model can clearly describe the link status and circuit signal flow of the system, in order to infer fault propagation of system. System failure probability propagation signal flow graph model fuzz the specific circuit connection structure, and the device model represent specific forms of device of system, and directed edge represent the link between device and device [3]. This model is mainly used for reasoning the optimal fault propagation path, in other words, when a fault occurs in the circuit system, the model of this system is to infer most likely occurring fault propagation path based on failure mode diffusion intensity. In the test verification, the failure mode is selected as the fault sample set, based on the Failure diffusion strength.

The main components of the system failure probability propagation signal flow diagram model can be described as follows:

- Finite number of functional units in the system $M=\left\{\mathrm{m}_{1}, \mathrm{~m}_{2}, \cdots, \mathrm{m}_{M}\right\}$, Each unit module represents an independent circuit unit with a relatively complete function in the system, which contain the location of the fault in the system and the fault pattern set for each unit;

- System failure mode set $F=\left\{\mathrm{f}_{1}, \mathrm{f}_{2}, \cdots, \mathrm{f}_{F}\right\}$, which represents specific failure modes in the system. And a system module may contain multiple failure modes.

Fault status F_State is represent by set FS $=$ \{normal, mild, generally, serious, fatal $\}$, and Specific fault state of set that is a vague concept and can't be measured by determined value is determined by fault signals or signs. It usually is interval range like the concept of Normal or serious, often described by fuzzy Interval of some performance parameters in engineering. So, this paper introduces the theory of fuzzy sets to describe the fault condition, First of all, we give the definition of fuzzy sets.

In order to elicit concept of fuzzy sets, firstly we present the concept of a basic set theory, known as the "universe" which is 
a common set and the entire question that we involve. In classical set theory, a relationship for any element $\mathrm{x}$ of Domain $\mathrm{U}$ and a set $\mathrm{A}$ only is $\mathrm{x} \in \mathrm{A}$ or $\mathrm{x} \notin \mathrm{A}$ two cases. So a collection can be described by the characteristic function, and each set has a characteristic function, for example:

$$
u_{A}(\mathrm{x})=\left\{\begin{array}{l}
1, x \in A \\
0, x \notin A
\end{array}\right.
$$

Function $u_{A}(\mathrm{x})$ is called the characteristic function of the set A, which scored the membership of the set A and also known as the membership function, and the definition of fuzzy set out is accordance with the concept of membership function.

Definition 1: Fuzzy subset $A$ on the domain $U=\{x\}$ is characterized by membership function $u_{A}(\mathrm{x})$ whose value size reflects the degree of membership of $\mathrm{x}$ to fuzzy set $\mathrm{A}$, and value is on the closed interval $[0,1]$.

For fault condition, the domain $\mathrm{U}=\{\mathrm{x}\}$ is a metric about fault signals or signs, and for fuzzy sets $\mathrm{FS}=$ \{normal, mild, in general, a serious, deadly , each state whose fuzzy set can be available described and characterized by triangular membership have a membership function $[9,10]$. Figure II is for the fault fuzzy state and it's triangular membership function schematic.

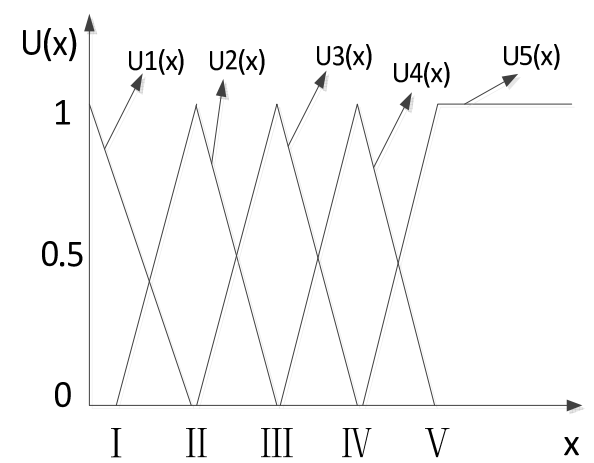

FIGURE II. FUZZY SETS OF FAULT STATUS AND MEMBERSHIP FUNCTIONS SCHEMATIC

In figure IV, $\mathrm{x}$ represents a measure of fault signals or signs which can be interactively obtain through man-machine interaction and described by triangular function, and $\mathrm{I} \sim \mathrm{V}$ respectively correspond one of the fault state of fuzzy set FS = \{normal, mild, in general, a serious, deadly\}.

- The edge set connecting nodes of each module $E\left(\mathrm{e}_{i j}\right) \quad(1 \leq \mathrm{i}, \mathrm{j} \leq \mathrm{M})$, where $\mathrm{e}_{i j}$ represents directed edges from point $i$ to node $j$. There exist two meanings: one represents the physical connection or the logical coupling between the modules; the two represents the transmission of the fault module.

- Directed graph $D G=\{\mathrm{M}, \mathrm{F}, \mathrm{E}\}$. M represents the module set, F represents the fault pattern set, E represents the edge to the edge.

\section{B. Principle of Fault Reasoning}

- The probability of failure propagation

Fault propagation probability $p_{i j}$ represents the size of the failure probability propagated from node $i$ to node $j$, which is mainly determined by physical or logical association between the modules system. In addition, it also affected by fault status of the induced failure and external random factors which included environmental factors and human factors etc. For example, in the system, there is a failure mode $f_{i}$ in the node $\mathrm{i}$, and fault influence degree of node $\mathrm{j}$ that induced by node $\mathrm{i}$ is $P=P_{1}, \mathrm{P}_{2}, \mathrm{P}_{3}, \mathrm{P}_{4}, \mathrm{P}_{5}$, So The fault propagation probability of node $\mathrm{i}$ to node $\mathrm{j}$ can be expressed as:

$$
P_{i j}=\sum_{k=1}^{5} u_{k}(\mathrm{x}) \mathrm{P}_{k}
$$

$P_{i j}$ indicates the fault propagation probability from node $\mathrm{i}$ to node $\mathrm{j}$, and $u_{k}(\mathrm{x})$ indicates the membership function of fuzzy set of fault state, and $\mathrm{X}$ indicates the corresponding signal of each fault.

\section{- Analysis of fault diffusion}

When the node $\mathrm{i}$ in the circuit system occur a failure, because of the connection between the nodes, this fault will affect the subsequent nodes which connected to node i, resulting in a fault of the subsequent nodes. And direction of fault spreading is mainly affected by two factors: (1) Fault will spread to one node which has a large probability of failure propagation; (2) the long connectivity range and degree of node will have an impact on the direction of propagation, so in the analysis of fault propagation direction, it need to make consider into these two factors. Failure pervasion fully considered these two factors, which is used as the weight of the edge $\langle\mathrm{I}, \mathrm{j}>$. More bigger the failure pervasion intensity are, the more likely it is said the fault will happen on the edge and will lead to the occurrence of subsequent failures[11,12].

The number of system unit is $\mathrm{n}$, and in the process of the $\mathrm{K}$ step fault propagation, the fault propagation probability of node $\mathrm{i}$ to node $\mathrm{j}$ is $P_{i j}{ }^{k}$, so the failure diffusion strength from node $\mathrm{i}$ to node $\mathrm{j}$ can be expressed as:

$$
I_{i j}{ }^{k}=w_{s}\left[w_{p} p_{i j}{ }^{k}+w_{d} d_{j}{ }^{k} / \sum_{j \in F_{k}} d_{j}{ }^{k}\right] ; i \in F_{k-1}
$$

$w_{p}$ represent fault propagation probability weights; $w_{d}$ represent the weight of the node degree; $p_{i j}{ }^{k}$ represent the $\mathrm{K}$ step fault propagation probability from node $\mathrm{i}$ to node $\mathrm{j} ; F_{k}$ represent the set of the $\mathrm{K}$ fault subsequent nodes; $d_{j}{ }^{k}$ represent the degree of $\mathrm{j}$ nodes which belong to step $\mathrm{k}$ of $F_{k}$, $w_{s}$ represent inter cluster communication department number. 
The weight in the system model generally used normalized parameter for the convenience of calculation, and the normalization of $I_{i j}{ }^{k}$ can be expressed as:

$$
I_{i j}{ }^{k}=I_{i j}{ }^{k} / \sum_{j \in F_{k}} I_{i j}{ }^{k} ; i \in F_{k-1}
$$

Through the above analysis, Fault will choose a path to spread whose failure diffusion strength is the largest. Based on the system modeling and analysis of the mutual connection of the edge of the failure of the diffusion strength, we can analyze the maximum probability of failure propagation path which is on actual circuit the most possible fault propagation paths. As shown in Figure III., the system is modeled as a schematic diagram of the failure, the black line indicates the maximum probability of the system fault propagation path.

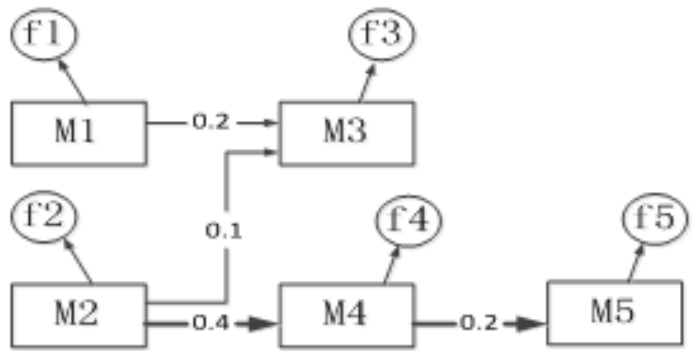

FIGURE III. ANALYSIS OF THE DIFFUSION PROCESS OF FAULT

\section{Based on Ant Colony Algorithm to Solve the FAULT DIFFUSION PATH}

In the large scale integrated circuit, device size is very large and link circuit is complex. Fault principle reasoning by using artificial method is clearly unreasonable. Therefore, it is necessary to use computer to calculate maximum probability fault propagation path in the circuit. In the computer circuit model is stored with adjacency matrix, and the numerical of the adjacency matrix represent fault pervasion intensity of node link. In the computer method that used to solve the optimal path have many kinds: Dijkstra algorithm, Ford algorithm, Floyd algorithm. In this paper, we choose the ant colony algorithm which is suitable for parallel operation to find the maximum probability fault propagation path.

Ant colony algorithm with which successfully solved the traveling salesman problem (TSP) was proposed by Italy scholar M.Dorigo in 1991 in his doctoral dissertation. It is a used to search the optimal probability path in the graph by using this algorithm whose the source of inspiration come from ants finding the shortest path in the process of finding food, and the basic idea is, when ants walk along a road to reach the end, it will return immediately, so that the path which is short of ants back and forth will use short time, resulting in shed more information on the road, there will be more ants that were attracted to generate more information, finally more and more ants gathered to the shortest path, thereby approximate to find the shortest path.
A mathematical model for solving the path with the maximum fault probability path of circuit can be expressed as follows:

$$
\begin{cases}\max \sum_{k} d_{k} & k=1,2, \cdots, n \\ \text { s.t } \prod_{k} p_{i j}{ }^{k} \leq 10^{-8} & i \in F_{k-1} ; j \in F_{k}\end{cases}
$$

Ants search for the next path according to the concentration of information. In the t time, ants's probability of selecting the follow-up point to walk who located on the node $\mathrm{i}$ can be expressed as follows:

$$
P_{i j}^{l}= \begin{cases}\frac{\left[\tau_{i j}\right]^{\alpha}\left[\eta_{i j}\right]^{\beta}}{\sum_{j \in N_{i}^{l}}\left[\tau_{i j}\right]^{\alpha}\left[\eta_{i j}\right]^{\beta}} & j \in N_{i}^{l} \\ 0 & \text { other }\end{cases}
$$

The $\eta_{i j}$ equals failure pervasion intensity $I_{i j}{ }^{k^{\prime}}$, alpha and beta is control information and heuristic information of ants select the path probability parameters, $N_{i}^{l}$ is node set which connected with node i. $\tau_{i j}$ represent information hormone.

$$
\tau_{i j}(t+1)=(1-\rho) \tau_{i j}(t)+\Delta \tau_{i j}
$$

$\mathrm{P}$ represent degree of volatilization, $\tau_{i j}(0)$ represent pheromone initialization value, $\Delta \tau_{i j}$ represent total increment of the pheromone and $\Delta \tau_{i j}=\sum_{l=1}^{N_{a}} \Delta \tau_{i j}{ }^{l}, N_{a}$ represent the number of ants, $\Delta \tau_{i j}{ }^{l}$ represent pheromone of individual ants. Using ant colony algorithm, according to the above set of parameters, it can be used to solve the problem of searching the maximum probability fault propagation path.

\section{THE APPLICATION EXAMPLE}

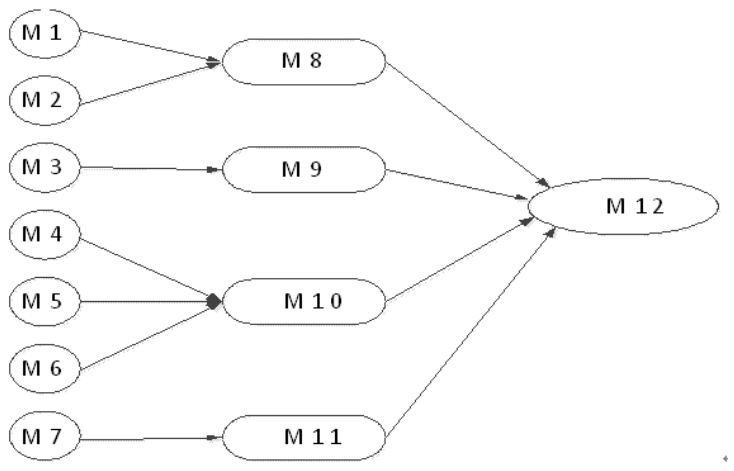

FIGURE IV. REFRIGERATION COMPONENTS AND ELECTRICAL CONNECTION DIAGRAM

A type of air missile is constituted by refrigeration components, vibration isolator, rectifier, shear bracket, lock 
device, a circuit box of 6 modules, due to many modules, each module processing method are similar, so the main refrigeration components built on fuzzy probability multi signal model, fault reasoning, to complete the verification test plan implementation link, Figure IV is the connecting fig of electrical refrigeration component.

According to the contract limit quality level of $q_{1}$, design value $q_{0}$, contractor risk $(\alpha)$, the use of risk $(\beta)$, by sampling scheme $(\mathrm{n}, \mathrm{C})$ and the contractor risk $(\alpha)$, use the risk $(\beta)$ relationship modeling formula (4) find the scheme of sampling for $(50,5)$. The validation process needs to allocated the total sample size which was proportionally and stratified to the 6 modules of the system, as known the weight of refrigeration components accounted for $w_{1}=0.121$ in the system, shows the fault sample allocation to the cooling module for the amount is $\mathrm{n} * \mathrm{w}=6$, the fault mode refrigeration components is shown in Table I, so 6 failure mode failure mode is needed to select from 12 failure modes consisting of the set.

TABLE I. INFORMATION OF COOLING ITS EACH COMPONENT FAILURE MODES

\begin{tabular}{|c|c|c|c|c|c|}
\hline $\begin{array}{l}\text { Subordinate } \\
\text { components }\end{array}$ & $\begin{array}{l}\text { Mode } \\
\text { number }\end{array}$ & Failure mode & $\begin{array}{l}\text { Subordinate } \\
\text { components }\end{array}$ & $\begin{array}{l}\text { Mode } \\
\text { number }\end{array}$ & Failure mode \\
\hline M1 & $\mathrm{fl}$ & Sealing ring A failure & M7 & f7 & Electromagnetic switch component failure \\
\hline M2 & f2 & The one-way valve failure & M8 & f8 & Pneumatic valve leakage \\
\hline M3 & f3 & Catheter parts failure & M9 & f9 & Cooling duct support export deformation \\
\hline M4 & $\mathrm{f} 4$ & Exhaust nozzle failure & M10 & $\mathrm{f10}$ & Pressure meter failure \\
\hline M5 & f5 & Sealing ring B failure & M1 1 & fl 1 & Electromagnetic switch leakage \\
\hline M6 & f6 & Adapter material defects & M12 & $\mathrm{f} 12$ & Refrigeration component failure \\
\hline
\end{tabular}

Based on Table I and Figure V., the fuzzy probability refrigeration component multi signal flow graph model could be established as shown in Figure IV.. Among them, the module set is $M=\left\{M_{1}, M_{2}, M_{3}, \cdots, M_{10}, M_{11}, M_{12}\right\}$, and the fault mode set is $F=\left\{f_{1}, f_{2}, f_{3}, \cdots f_{10}, f_{11}, f_{12}\right\}$, and the fault prior probabilities respectively for F_Probability $=\{0.029$, $0.012,0.012,0.035,0.0175,0.012,0.00 \overline{6}, 0.007,0.041,0.72$, $0.058,0.07\}$.

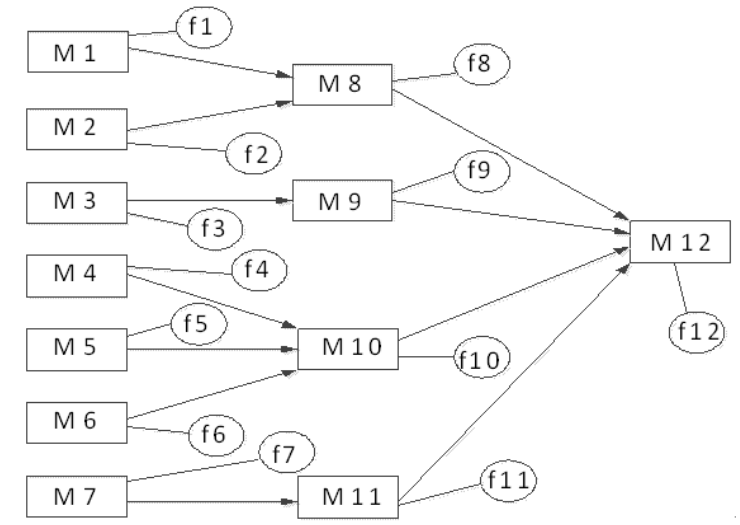

FIGURE V. FUZZY PROBABILITY SIGNAL FLOW DIAGRAM OF REFRIGERATION COMPONENTS

Next to execute fault propagation reasoning about failure modes $\mathrm{fl}$ of the component M1, according to records, we know fault status P_State(f1) $=\{$ serious $\}$, therefore obtain F_Belief $\left(f_{1}\right)=0 . \overline{9} 5$ by the relationship of fault state and membership functions and assume fault confidence occurred judgment threshold Limitation $=0.3$. Due to the degree of influence between failures D Influence is mainly determined by physical or logical relation of system modules, so can launch the influence degree of each edge of refrigeration components:
D_Influence $\left(\mathrm{f}_{1}, \mathrm{f}_{8}\right)=0.71$, D_Influence $\left(\mathrm{f}_{2}, \mathrm{f}_{8}\right)=0.29$, D_Influence $\left(\mathrm{f}_{3}, \mathrm{f}_{9}\right)=1.0 \quad, \quad$ D_Influence $\left(\mathrm{f}_{4}, \mathrm{f}_{10}\right)=0.5$, D_Influence $\left(\mathrm{f}_{5}, \mathrm{f}_{10}\right)=0.25$, D_Influence $\left(\mathrm{f}_{6}, \mathrm{f}_{10}\right)=0.167$, D_Influence $\left(\mathrm{f}_{7}, \mathrm{f}_{11}\right)=0.083$, D_Influence $\left(\mathrm{f}_{8}, \mathrm{f}_{12}\right)=1.0$, D_Influence $\left(\mathrm{f}_{9}, \mathrm{f}_{12}\right)=0.226$, D_Influence $\left(\mathrm{f}_{10}, \mathrm{f}_{12}\right)=0.065$, D_Influence $\left(f_{11}, f_{12}\right)=0.323$.

The fault f1 reasoning propagation and failure mode sample set selection rules are as follows:

STEP1: Reasoning fault mode fl's successor possible propagation fault mode set F_Possibility $\left(\mathrm{f}_{1}\right)=\left\{\mathrm{f}_{8}, \mathrm{f}_{9}\right\}$;

STEP2: Under the fault mode f1 inducing, calculate failure confidence level of successor possible propagation fault mode set. Since F_Belief $\left(\mathrm{f}_{1}\right)>$ Limition, and according to the confidence is greater than threshold, failure mode $\mathrm{fl}$ apparently spread to $\mathrm{f8}$, and because fault propagation confidence of failure $\mathrm{fl}$ and $\mathrm{f8}$ D_Belief $\left(\mathrm{f}_{1}, \mathrm{f}_{8}\right)=$ F_Belief $(\mathrm{fl}) \times$ D_Influence $(\mathrm{f} 1, \mathrm{f} 8)=1 * 0.71$, so confidence level of $\mathrm{f} 8$ fault mode $F$ Belief $(\mathrm{f} 8)=\mathrm{D}$ Belief $(\mathrm{fl}, \mathrm{f8}) \times \mathrm{F}$ Probability $(\mathrm{f8})=$ $0.71 * \overline{0.007}$, due to $\mathrm{F} \bar{B}$ elief (f8) $<$ Limitation, known failure mode $\mathrm{f} 8$ failed to spread to $\mathrm{f} 12$. So the propagation path of fault mode $\mathrm{fl}$ is $\mathrm{fl}->\mathrm{f} 8$;

STEP3: Subsequent failure mode set of fault mode $\mathrm{fl}$ F_Set $=\left\{f_{8}\right\}$ and the number of diffusion of fault mode $\mathrm{fl}$ is one;

STEP4: Similarly reason other failure modes, only known confidence level of fault mode $\mathrm{f} 4$ greater than Limitation, and subsequent failure mode set of failure $\mathrm{f} 4$ is $\mathrm{F} \_\mathrm{Set}=\left\{\mathrm{f}_{10}\right\}$;

STEP5: Select fault mode $\mathrm{fl}$ and $\mathrm{f} 4$, and using the computer randomly generated four mutually different random numbers and extract corresponding failure mode, for example: f6, f8, f11, 
f12. By f1, f4, f6, f8, f11, f12 together constitute failure to complete the test validation sample set design.

The number of sample proportionally stratified assigned to the refrigeration components is six, so it is necessary to extract the six of twelve failure mode from refrigeration components. Simple random sampling random extract six failure modes, and did not consider the failure modes propagating. In order to improve the validated reliability and consumer risk, we study the advanced sampling method based on fault propagation successor mode set. This method is divided into two steps: the first step is the establishment of fuzzy probability multi-signal model and the reasoning of subsequent failure mode set, we can see from the above subsequent failure mode set of failure $\mathrm{fl}$ is $\mathrm{F} \_\mathrm{Set}=\left\{\mathrm{f}_{8}\right\}$, failure $\mathrm{f} 4$ is $\mathrm{F} \_\mathrm{Set}=\left\{\mathrm{f}_{10}\right\}$, so the number of subsequent failure mode of the failure $\mathrm{fl}$ and $\mathrm{f} 4$ is one and should be extracted as a failure sample set. The second step is to extract the remaining four failure modes, these four failure modes use simple random sampling method for sampling. The spread-type failure mode is extracted and the remaining failure modes are numbered by natural numbers, randomly generated by computer random number, and extracted the corresponding failure mode data. This gives a sampling method based on fault propagation subsequent failure mode set to optimize the structure of sampling. In order to be compared with simple random, both results of random sampling and advanced sampling are given in Table II.

TABLE II. THE COMPARISON OF OPTIMIZED SAMPLING METHOD BASED ON FAULT PROPAGATION SUCCESSOR PATTERN SET AND SIMPLE SAMPLING.

\begin{tabular}{|c|c|c|c|c|}
\hline Name & Failure mode & $\begin{array}{c}\text { The number } \\
\text { of failure } \\
\text { mode } \\
\text { successor }\end{array}$ & $\begin{array}{c}\text { Simple } \\
\text { sampling }\end{array}$ & $\begin{array}{c}\text { Advanced } \\
\text { sampling } \\
\text { methods }\end{array}$ \\
\hline M1 & $\begin{array}{l}\text { Sealing ring } \mathrm{A} \\
\text { failure }\end{array}$ & 1 & $\sqrt{ }$ & $\sqrt{ }$ \\
\hline M2 & $\begin{array}{l}\text { The one-way } \\
\text { valve failure }\end{array}$ & & $\sqrt{ }$ & \\
\hline M3 & $\begin{array}{l}\text { Catheter parts } \\
\text { failure }\end{array}$ & & & $\sqrt{ }$ \\
\hline M4 & $\begin{array}{l}\text { Exhaust nozzle } \\
\text { failure }\end{array}$ & 1 & $\sqrt{ }$ & \\
\hline M5 & $\begin{array}{l}\text { Sealing ring B } \\
\text { failure }\end{array}$ & & & $\sqrt{ }$ \\
\hline M6 & $\begin{array}{c}\text { Adapter material } \\
\text { defects }\end{array}$ & & $\sqrt{ }$ & $\sqrt{ }$ \\
\hline M7 & $\begin{array}{l}\text { Electromagnetic } \\
\text { switch component } \\
\text { failure }\end{array}$ & & & \\
\hline M8 & $\begin{array}{c}\text { Pneumatic valve } \\
\text { leakage }\end{array}$ & & $\sqrt{ }$ & $\sqrt{ }$ \\
\hline M9 & $\begin{array}{l}\text { Cooling duct } \\
\text { support export } \\
\text { deformation }\end{array}$ & & $\sqrt{ }$ & \\
\hline M10 & $\begin{array}{l}\text { Pressure meter } \\
\text { failure }\end{array}$ & & & \\
\hline M11 & $\begin{array}{l}\text { Electromagnetic } \\
\text { switch leakage }\end{array}$ & & & $\sqrt{ }$ \\
\hline M12 & $\begin{array}{c}\text { Refrigeration } \\
\text { component failure }\end{array}$ & & & \\
\hline
\end{tabular}

In summary, the fuzzy probability signal model can effectively describe the fault propagation diffusion process.
Advanced sampling methods based on subsequent failure mode set of fault propagation can extract a large degree of fault diffusion strength failure mode, effectively reducing the risk of failure due to the spread of type test is not brought to the consumer.

\section{ACKNOWLEDGMENT}

This work was supported in part by the Fundamental Research Funds for the Central Universities of China (Grant No. ZYGX2015J074).

\section{REFERENCES}

[1] GJB3385-1998. Test and diagnostic terminology [S].Beijing: National Defense Military Standard Publishing, 1998.

[2] Zhong Tian, Jun You Shi.System design for testability analysis and verification [M].Beijing: Beijing University of Aeronautics and Astronautics Press,2003.

[3] H A N Guang - chen, S U N S hu - dong, S I S hu - bi n, FU Pi n g. Research on model of fault diagnosis and propagation in complex system [J]. Computer Integrated Manufacturing System,2005, 11(6):794798.

[4] Department of Defense.MIL-STD-471A Interim Notice 2, Demonstration and Evaluation of Equipments / System Built-in Test / External Test / Fault Isolation / Testability Attributes and Requirements[S]. 1978.

[5] P. N. Bowerman, E. M. Scheuer. Calculation of the binomial cumulative distribution function[J]. IEEE Trans.Reliability,1990,39(7): 162 166.

[6] LI Tian-mei, QIU Jing, LIU Guan-jun, XU Cong-qi.A Method of Failure Sample Selection Based onFailure Pervasion Intensity [J]. Ordnance Journal, 2008, 28(7): 829-833.

[7] Yuzhu Zhang, Hu Ziwei, Cao Shimin, etc. Maintainability verification test and evaluation principles [M]. Beijing: Defense Industry Press, 2006

[8] S. Deb, K. R.Pattipati, R. Shrestha. QSI's Integrated Toolset. Proc. IEEE Autotestcon, Anaheim, CA, 1997: 408-421.

[9] Pei Wang Zhuang, Li Hongxing. Fuzzy system theory and fuzzy computer [M]. Beijing: Science Press, 1996.

[10] Li Tianmei, GAO Xinyu, Qiu Jing, Liu Guanjun. A Failure Sample Selection Method Considering Failure Pervasion Intensity in Testability Demonstration Test. Chinese Journal of Acta Armamentar II, 2009, 12(9): 56-62.

[11] Gao Xinyu. Research on Failure Modeling Technology of Testability Virtual Evaluation[D]. National University of Defense Technology, 2009.

[12] Kao W, Iyer R.K. DEFINE: A Distributed Fault Injection and Monitoring Environment [A]. Proc. Workshop Fault-Tolerant Parallel and Distributed Systems [C]. 1994:511-518. 